\title{
Solid Swallow Examination During High Resolution Manometry and EGJ-Distensibility Help Identify Esophageal Outflow Obstruction in Non-obstructive Dysphagia
}

\author{
Fritz Ruprecht Murray ${ }^{1}$ (D) - Lara Maria Fischbach ${ }^{1} \cdot$ Valeria Schindler $^{1} \cdot$ Larissa Schnurre $^{1} \cdot$ Juliane Marie Hente $^{1}$. \\ Aurora Tatu ${ }^{1} \cdot$ Daniel Pohl $^{1}$ (B)
}

Received: 13 August 2020 / Accepted: 27 January 2021 / Published online: 20 February 2021

(c) The Author(s) 2021

\begin{abstract}
Single water swallow (SWS) high-resolution manometry (HRM) may miss relevant esophageal motility disorders. Solid test meal (STM) during HRM and lately the functional lumen imaging probe (FLIP) have been shown to be of diagnostic value in the assessment of motility disorders. We aimed to assess the diagnostic yield of STM and FLIP in non-obstructive dysphagia (NOD). Patients assessed for dysphagia with both HRM and FLIP between April 2016 and August 2019 were analyzed for signs of non-obstructive EGJ outflow obstruction (EGJOO) according to Chicago Classification 3.0 (CCv3) and $\mathrm{CC}$ adapted for the use with solid swallows (CC-S), followed by an individual group-specific analysis. Five subjects without dysphagia served as control group. Standard HRM- and FLIP-values as well as esophagograms and Eckardt Scores were analyzed. Forty-two patients were identified (male/female, 14/36, median age 62). Twenty-five (59.5\%) were diagnosed with EGJOO during STM only (=SWS-negative patients; CC-S). The EGJ distensibility index (EGJ-DI) of symptomatic patients was significantly lower compared to the control group $(p=0.006)$. EGJ-DI was $<3 \mathrm{~mm}^{2} / \mathrm{mmHg}^{\mathrm{in}} 67 \%$ and $88 \%$ of patients diagnosed according to $\mathrm{CC}-\mathrm{S}$ and $\mathrm{CCv} 3$, respectively. The IRP during STM showed a significant association to the corresponding EGJ-DI values $(p<0.001)$. Seventy-six percent of patients received treatment because of additional STM evaluation with a favorable clinical response rate of $89 \%$. STM and FLIP identify EGJOO in symptomatic patients with normal SWS during HRM. STM resembles an inexpensive and clinically meaningful option to diagnose motility disorders and helps to select patients for interventional treatment.
\end{abstract}

Keywords Solid swallow high-resolution manometry · FLIP · Esophagogastric outlet obstruction · Non-obstructive dysphagia

Fritz Ruprecht Murray and Lara Maria Fischbach contributed equally to this work.

Daniel Pohl

daniel.pohl@usz.ch

Fritz Ruprecht Murray

fritz.murray@usz.ch

Lara Maria Fischbach

lara.fischbach@usz.ch

Larissa Schnurre

larissa.schnurre@usz.ch

\section{Introduction}

Achalasia and esophagogastric junction outlet obstruction (EGJOO) are major motility disorders with impaired relaxation of the lower esophageal sphincter (LES). Achalasia is a rare but well-characterized disease, caused by a degeneration or dysfunction of inhibitory postganglionic

Juliane Marie Hente

julianemarie.hente@usz.ch

Aurora Tatu

aurora.tatu@usz.ch

Division of Gastroenterology and Hepatology, University Hospital Zurich, Raemistrasse 100, 8091 Zurich, Switzerland 
neurons in the distal esophagus [1]. In contrast, EGJOO is less clearly characterized and may be caused by anatomic obstacles, such as a large hiatal hernia, distal esophageal stricture or fundoplication; can be of functional origin or may represent an early stage of achalasia [2]. Furthermore, EGJOO has been shown to be associated with opioid and excessive alcohol consumption [3].

To date, the metrics of single water swallows (SWS) collected during high-resolution manometry (HRM) are routinely used for the diagnosis of these disorders, based on the Chicago Classification Version 3.0 (CCv3) [4]. However, HRM may miss motility disorders in patients with non-obstructive dysphagia (NOD) [5, 6], leaving them without a definite diagnosis and thus uncertain further management. The inclusion of a standardized solid test meal (STM) to HRM has been shown to increase the diagnostic sensitivity of HRM with the possibility of establishing motility disorders with the observations made during STM [7]. In response to this, an adaptation of the Chicago Classification (CC) adapted for the use with solid swallows (CC-S) was recently suggested, proposing a diagnostic hierarchy for major motility disorders during STM [8]. In this classification an integrated relaxation pressure (IRP) $>25 \mathrm{mmHg}$ in $\geq 2$ swallows was defined as pathologic.

The endoluminal functional lumen imaging probe (FLIP) is being increasingly used as an additional diagnostic tool for the assessment of esophageal function, including motility [9]. In addition, FLIP provides comprehensive information regarding LES physiology by measuring the EGJ distensibility index (EGJ-DI), a function of the EGJ cross-sectional area (CSA) and the FLIP intra-balloon pressure [10-14]. Recently Triggs et al. published a study showing FLIP to be useful to identify EGJOO patients who benefit most likely from achalasia-type treatment [14]. While focusing on treatment outcomes, all included patients were diagnosed according to single water swallows only, leaving the question of how to proceed with the relevant proportion of dysphagia patients without findings during single swallow HRM unanswered.

In recent years, FLIP studies have been able to demonstrate that a pathologic EGJ-DI identifies achalasia in patients with suggestive radiological and clinical features not fulfilling formal HRM criteria for diagnosis of achalasia [15]. Until now, EGJOO has been largely neglected in EGJDI studies, especially regarding a potential diagnostic benefit in symptomatic patients not fulfilling CCv3 criteria in HRM.

The aim of this study was to further assess the diagnostic yield of both STM and FLIP findings in non-achalasia patients with symptomatic NOD. To the best of our knowledge this is the first study, presenting clinically relevant outcomes of additional diagnostic procedures resulting in achalasia-type treatment in $\mathrm{CCv} 3$ non-obstructive but symptomatic patients. In addition, the results of this study for the first time identify EGJ-DI values in EGJOO patients.

\section{Materials and Methods}

\section{Patients}

Ninety-three patients with clinically relevant dysphagia, diagnosed with EGJOO either during SWS according to CCv3 or during STM between April 2016 and August 2019 were analyzed. For each patient, age, sex, current medication, results of previous upper endoscopy, medical history, clinical symptoms and Eckardt Score (ES) were documented prior to HRM. All patients were assessed with both HRM, routinely including SWS and STM, and FLIP according to the routine clinical management of our clinic. Further inclusion criteria were age $\geq 18$ years and signed general informed consent. Patients diagnosed with achalasia according to $\mathrm{CCv} 3$ were not considered. Fifty-one patients were excluded for the following reasons: obstructive dysphagia (Schatzki, $n=1$; eosinophilic eosophagitis, $n=1$; large axial hernia, $n=1$; previous mediastinitis with fibrosis, $n=1$; distal eosophageal spasm, $n=2$ ), previous interventions at the EGJ (fundoplication, $n=13$; previous dilation, $n=11$ ), upper GI surgery $(n=1)$, current opiate intake, $n=13)$ and/or pulmonary $(n=1)$ and gastric $(n=1)$ cancer; 5 other patients were excluded for rejected general informed consent. In addition to symptomatic patients, datasets of five patients without symptomatic dysphagia with an ES of 0 points who had received both HRM and FLIP for other reasons (e.g. pyloric dysfunction as a clinical lead for gastroparesis, gastric belching or gastroesophageal reflux disease) were documented. During these investigations, the EGJ was routinely examined and thus clinical data of non-dysphagia patients was gathered. All investigations were conducted according to the standard clinical workup of symptomatic dysphagia of our institution. Datasets were analyzed after approval of the Zurich Ethics Committee (KEK-Nr: 2017-00930).

Prior to further analysis, patients were separated into two groups: the first group included patients with pathologic patterns during STM according to CC-S (STM-group). All of these patients had IRP values of $<15 \mathrm{mmHg}$ during SWS (= SWS-negative) and at least 2 swallows with IRP $>25 \mathrm{mmHg}$ during STM and a normal swallow pattern during SWS. In contrast, group two (SWS-group), meant to function as a comparative group, included patients diagnosed with EGJOO during SWS according to CCv3 (IRP $\geq 15 \mathrm{mmHg}$ and non-achalasia swallow pattern). All patients considered pathologic during SWS also met criteria regarded as pathologic during STM. An additional third group, meant to function as a control group, consisted of patients without symptomatic dysphagia 
$(E S=0)$. All calculated IRP values both in SWS and STM were $<15 \mathrm{mmHg}$. No obstructive, spastic or hypercontractile swallow patterns were demarcated during SWS or STM. Of note, patients in the control group were considerably younger than those included into the STM- and SWS-group.

\section{Procedures}

The analysis of all HRM and STM data was conducted by members of the Functional Diagnostic Department of the University Hospital Zurich (all authors) with a final review of the head of the department (DP). All endoscopic procedures (FLIP) were conducted by one endoscopist (DP).

\section{Standard HRM Procedure}

HRM was performed with a 36 channel solid-state HRM catheter (Manoscan 360, Sierra Scientific Instruments, Given Imaging, Los Angeles, CA, USA). The application, calibration procedure and the post study-preparation procedure of the data has been described in detail elsewhere [16, 17]. The applied protocol included ten SWS with a volume of $10 \mathrm{ml}$ administered in semi-upright position, followed by a rapid drink challenge of $100 \mathrm{ml}$. Afterwards, a STM was consumed by each patient, followed by another rapid drink challenge. All HRM studies were analyzed with ManoView ESO version 3.0.1., followed by classification according to CCv3 [4].

\section{Procedure and Analysis of STM}

STM consisted of $200 \mathrm{~g}$ of freshly cooked salted plain rice (Uncle Bens, Brussels, Belgium; $270 \mathrm{kcal}$ ). STM analysis was conducted in accordance to previous studies and results were classified according to CC-S $[7,8,18]$. For each patient, individual frames were manually inserted into the recorded STM period (ManoView ESO version 3.0.1) to calculate the IRP for every esophageal contraction during STM. According to previously published literature, IRP values of $25 \mathrm{mmHg}$ in $\geq 2$ solid swallows during STM were considered pathologic, leading to the diagnosis of EGJOO [8].

\section{FLIP Investigation EGJ}

EGJ-DI measurements were performed with FLIP probe system (EndoFLIP®, Crospon Ltd, Galway, Ireland) during upper endoscopy. The characteristics, technical details and exact application of this device are described elsewhere [13, 15, 19, 20]. In short, the FLIP was introduced during upper endoscopy in close proximity of the EGJ. After retracting the endoscope, the final positioning of the balloon was guided by the FLIP technology showing a narrowing of the balloon. Two different device sizes were used due to logistic reasons:
EndoFLIP-325 (EF-325) and EndoFLIP-322 (EF-322). The characteristics, technical details and exact procedure of this device are described elsewhere [13, 15, 19]. EF-325 investigations were started at a catheter volume of $30 \mathrm{ml}$ and the EF-322 at $40 \mathrm{ml}$. Volumes were increased in $10 \mathrm{ml}$ steps to a maximum of $50 \mathrm{ml}$ (EF-325) and $70 \mathrm{ml}$ (EF-322).. During examination, cross sectional area (CSA), diameter, EGJ-DI and balloon pressure were recorded following a standardized protocol. Depending on the catheter type, different filling volumes for the reference values were used in order to guarantee an adequate balloon pressure $(>20 \mathrm{mmHg})$ in accordance to published normative values [13, 19, 21]: $40 \mathrm{ml}$ and $60 \mathrm{ml}$ for the EF-325 and -322, respectively. An EGJ-DI of $<3 \mathrm{~mm}^{2} / \mathrm{mmHg}$ with a balloon pressure of at least $20 \mathrm{mmHg}$ was considered pathologic $[13,21]$.

\section{Timed Barium Esophagogram and Eckardt Score}

Results of pre-and post-interventional timed barium esophagograms (TBE) were added to the analysis. TBE images were taken in upright position 1, 3 and 5 min after ingestion of a standard low-density liquid barium swallow. In case of stasis, the height of the barium column was measured at each respective time point. A reduction of the column height was adopted as positive therapy response. For clinical follow-up, ES was reported pre- and post-interventionally. An improvement in the ES was considered positive as either a reduction of 3 points to baseline or a total ES below 3 points.

\section{General Information Regarding Treatment Decisions}

Up to the analysis of the underlying study, treatment decisions in our clinic in case of EGJOO depended on an analysis of varies diagnostic parameters consisting of ES, HRM (SWS + STM), TBE and the individual desire of patients. Due to the lack of normative values and clinical evidence, FLIP metrics were not part of treatment decisions of patients included in this manuscript.

\section{Endpoints}

The primary endpoint was the assessment of the diagnostic yield of both STM and FLIP findings in non-achalasia patients with symptomatic NOD as follows: Corresponding STM-IRP and EGJ-DI values were analyzed, with focus on SWS-negative patients with pathologic STM findings according to CC-S. In addition, EGJ-DI values of symptomatic patients and an asymptomatic control group were compared.

The secondary endpoint was an analysis of FLIP and STM findings in SWS-negative patients in regard to therapeutic consequences, focusing on TBE and ES. 


\section{Statistical Analysis}

Data analysis was performed with $\mathrm{R}$ version 3.5.2 (R Foundation for Statistical Computing, Vienna, Austria, 201812-20). To compare data of different groups Wilcoxon signed-rank test as well as generalized linear models were used. In order to analyze the relation between STM-IRP and distensibility, linear regression analysis was performed. A $p$ value $<0.05$ was regarded as significant. The continuous data is displayed in median (range) or number (percent of total).

\section{Results}

\section{Patient and Group-Specific Characteristics}

All included patients were primarily assessed with HRM for dysphagia, followed by an additional examination with FLIP. A total of 42 patients (men 22/42 [47\%], median age, 62 years [range 24-88]) matched the above mentioned inclusion criteria. All group specific characteristics are displayed in Table 1.

\section{Yield of Additional Analysis of STM in Patients with Normal HRM According to CCv3}

All (100\%) patients included in the STM-group $(n=25)$ were classified as normal during SWS according to CCv3 (=SWS-negative). Accordingly, none of these patients (all of them symptomatic) would have been considered for achalasia type treatment if only accessed with conventional SWS HRM.

\section{Association of STM-IRP and EGJ-DI}

Linear regression analysis of the IRP during STM in all investigated patients (STM-group + SWS-group + control group) showed a statistically significant association to the corresponding EGJ-DI values $(p<0.001)$. Statistically, a decrease of $1.0 \mathrm{~mm}^{2} / \mathrm{mmHg}$ in EGJ-DI was associated with an increase of $2.2 \mathrm{mmHg}$ in STM-IRP values.
Table 1 Group specific characteristics

\begin{tabular}{|c|c|c|c|}
\hline & STM-group & SWS-group & Control-group \\
\hline \multicolumn{4}{|l|}{ Characteristics } \\
\hline Number of patients & 25 & 17 & 5 \\
\hline Gender $(\mathrm{m} / \mathrm{w})$ & $11 / 25$ & $7 / 17$ & $4 / 5$ \\
\hline Age (median, range) & $62,28-88$ & $72,47-82$ & $28,24-53$ \\
\hline \multicolumn{4}{|l|}{ IRP SWS (mmHg) } \\
\hline Median & 9.0 & 19.7 & 4.4 \\
\hline Range & $4.2-14.8$ & $15.8-38.2$ & $0.1-7.8$ \\
\hline \multicolumn{4}{|l|}{ IRP STM (mmHg) } \\
\hline Median & 21.9 & 26.7 & 2.5 \\
\hline Range & $15.1-35.1$ & $17.8-35.3$ & $1-8.9$ \\
\hline \multicolumn{4}{|l|}{ Type FLIP used } \\
\hline EF-325 & 18 & 17 & 4 \\
\hline EF-322 & 7 & 0 & 1 \\
\hline \multicolumn{4}{|l|}{ EGJ-DI $\left(\mathrm{mm}^{2} / \mathrm{mmHg}\right)$} \\
\hline $\mathrm{EF}-325$ at $40 \mathrm{ml}$ (median, range) & $2.1,0.3-7.0$ & $1.8,0.7-5.6$ & $6.9,3.6-9.4$ \\
\hline $\mathrm{EF}-322$ at $60 \mathrm{ml}$ (median, range) & $1.5,0.8-2.7$ & & 3.1 \\
\hline EGJ-DI $<3 \mathrm{~mm}^{2} / \mathrm{mmHg}$ & $19(67 \%)$ & $15(88 \%)$ & 0 \\
\hline \multicolumn{4}{|l|}{ Eckardt Score } \\
\hline Median & 3 & 4 & 0 \\
\hline Range & $1-10$ & $2-9$ & \\
\hline \multicolumn{4}{|l|}{ TBE (number of patients) ${ }^{\mathrm{a}}$} \\
\hline Abnormal motility & 4 & 5 & \\
\hline Stasis & 14 & 9 & \\
\hline After 3 min (median hight in $\mathrm{cm}$, range) & $14(5,2-11)$ & $9(3,1-6.5)$ & \\
\hline After 5 min (median hight in $\mathrm{cm}$, range) & $7(5,0.5-11)$ & $1(3)$ & \\
\hline
\end{tabular}

IRP integrated relaxation pressure, SWS single water swallows, STM standard test meal, FLIP functional lumen imaging probe, $E F$ EndoFLIP, EGJ-DI EGJ distensibility index, TBE timed barium esophagogram

${ }^{a}$ Only 23/25 patients in STM-group and no patient in the control-group received TBE 


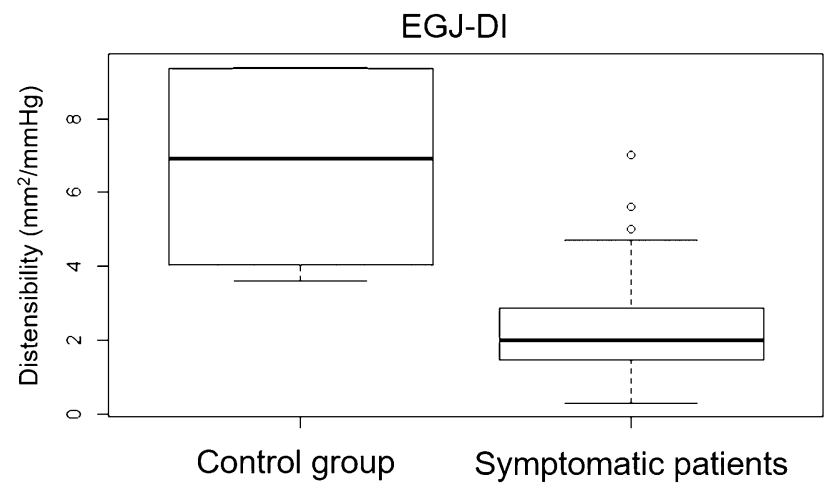

Fig. 1 EGJ-DI results in control group

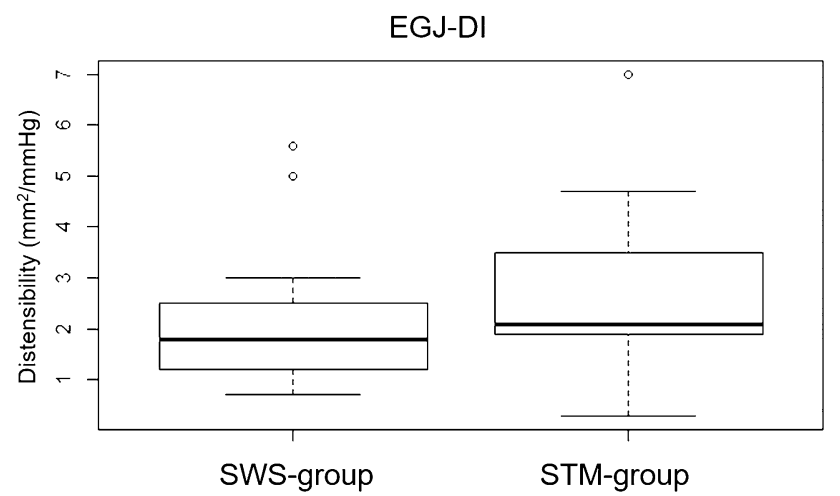

Fig. 2 EGJ-DI results in symptomatic patiens (SWS-group and STMgroup)

\section{Comparison of EGJ-DI Between Groups}

EGJ-DI in symptomatic patients (STM- and SWS-group combined) was significantly lower (median, $2.0 \mathrm{~mm}^{2} / \mathrm{mmHg}$; range $0.3-7.0 \mathrm{~mm}^{2} / \mathrm{mmHg}$ ) than in the control group (median $6.9 \mathrm{~mm}^{2} / \mathrm{mmHg}$; range $\left.3.6-9.4 \mathrm{~mm}^{2} / \mathrm{mmHg}\right)(p=0.006$, shown in Fig. 1). Values of the STM- (median $2.1 \mathrm{~mm}^{2} /$ $\mathrm{mmHg}$; range $0.3-7.0 \mathrm{~mm}^{2} / \mathrm{mmHg}$ ) and SWS-group (median, $1.8 \mathrm{~mm}^{2} / \mathrm{mmHg}$; range $0.7-5.6 \mathrm{~mm}^{2} / \mathrm{mmHg}$ ), however, did not significantly differ from one another $(p=0.109$, shown in Fig. 2). Figure 3 illustrates the association between IRP values and EGJ-DI in the three subgroups.

\section{Achalasia-Type Treatment in SWS-Group}

In the SWS-group $9 / 17$ patients (53\%) received interventional treatment with the EsoFLIP device, which has been implemented in the management of the treatment of EGJ disorders in our clinic (first results of the treatment of achalasia patients have been published; [22]). The median distensibility of these patients was $1.6 \mathrm{~mm} 2 / \mathrm{mmHg}$ (range $0.7-2.0 \mathrm{~mm}^{2} / \mathrm{mmHg}$ ). Pre-interventional TBE showed stasis in $6 / 9$ patients $(67 \%)$ and 3/9 (33\%) showed abnormal motility. All patients were dilated once, until the median diameter of $26 \mathrm{~mm}$ (range 19-26 mm). Of these 9 patients, 6 received a second EsoFLIP-controlled dilatation (median diameter, $27 \mathrm{~mm}$; range $26-29 \mathrm{~mm}$ ). Clinical and radiological follow-up was performed in a median of 10 days (range 4-33) after treatment. Post-interventionally, the median ES improved from 4 (range 3-9) to 0 (range 0-2) in all treated patients. TBE, performed in $8 / 9$ after the first and in $4 / 6$ patients after the second dilation, showed a reduction of stasis or normal motility patterns in all treated patients. Eight patients did not receive achalasia-type treatment. Three (37.5\%) had a normal distensibility $\left(\geq 3 \mathrm{~mm}^{2} / \mathrm{mmHg}\right), 3 / 8$ (37.5\%) had a reduced distensibility but normal TBE and clinically improved after a proton pump inhibitor trial, and
Fig. 3 Association of IRP values and EGJ-DI

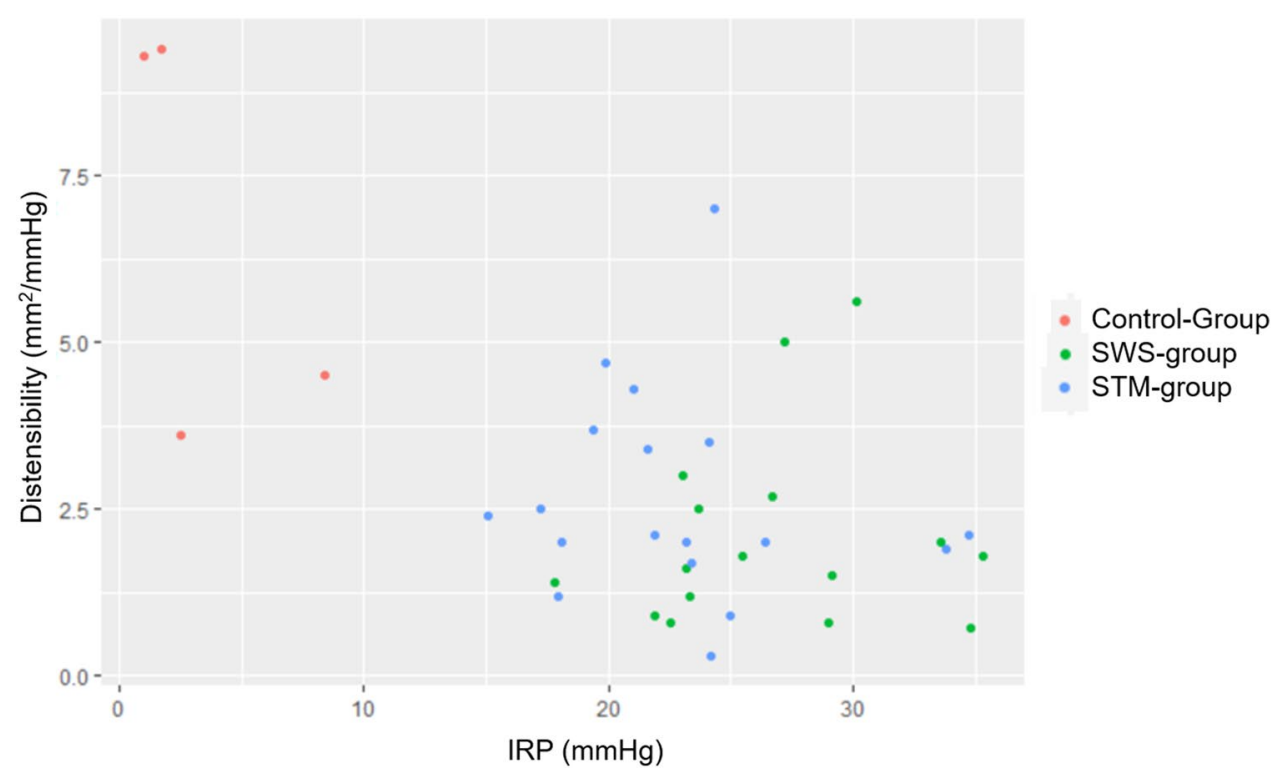


2/8 $(25 \%)$ declined treatment (despite reduced distensibility and abnormal TBE).

\section{Consequences of Motility Disorder Demarcation During STM}

Nineteen patients in the STM-group (76\%) received achalasiatype treatment as a consequence of pathologic findings during STM. The majority $(16 / 19,84 \%)$ received at least one balloon dilation. Most $(15 / 16,94 \%)$ of these dilations were conducted with the EsoFLIP device. Of these, 7 (7/15) received a second EsoFLIP-controlled dilation and three (3/15) were additionally treated with the Rigiflex balloon system $(35 \mathrm{~mm})$. In the remaining $5(5 / 15)$ patients, a second dilation was not necessarry. One patient (1/16) was treated solely, but twice with the Rigiflex balloon system. The remaining three patients (3/19, $16 \%)$ were treated with Botox-injections.

In the subgroup of treated (SWS-negative) patients, median EGJ-DI was $2.1 \mathrm{~mm}^{2} / \mathrm{mmHg}$ (range $0.3-4.7 \mathrm{~mm}^{2}$ / $\mathrm{mmHg}$ ) and TBE (performed in 18/19 patients) showed stasis in $72 \%$. Three of the treated patients had an EGJDI $\geq 3 \mathrm{~mm}^{2} / \mathrm{mmHg}$. However, these patients showed stasis or abnormal motility during TBE, and reported an $\mathrm{ES} \geq 4$. Of the six patients that did not receive treatment, two patients (33\%) showed an EGJ-DI $\geq 3 \mathrm{~mm}^{2} / \mathrm{mmHg}$ and an ES $<3$. Three showed normal findings during TBE and/or ES $<3$ and one patient showed a significant symptom reduction $(\mathrm{ES}=0)$ following treatment with proton pump inhibitors and no stasis in TBE (EGJ-DI $=2.0 \mathrm{~mm}^{2} / \mathrm{mmHg}$ ).

If performed $(15 / 19,79 \%)$, post-interventional TBE (performed in a median of 15 days post treatment; range 6-77) showed an improved outcome after completed treatment in all patients. In seven patients (47\%) stasis in the 5 min image remained with reduced median height of $2 \mathrm{~cm}$ compared to $5 \mathrm{~cm}$ pre-interventionally. Eight patients (53\%) showed no stasis after treatment, 5 of these had stasis and 3 abnormal motility and delayed passage pre-interventionally. In accordance, the post-interventional ES was significantly reduced with median values of 5 (range 1-10) and one (range $0-4$ ) pre- and post-interventionally ( $p$ value $<0.001$ ). Thirteen patients $(69 \%)$ showed both a reduced ES of $\geq 3$ points and an ES $<3$ after completed therapy. Two patients (11\%) showed an ES $<3$ and another $2(11 \%)$ a reduction of $\geq 3$ points. Only 2 patients $(11 \%)$ showed neither a reduction $\geq 3$ points nor an ES of $<3$ after completed therapy. In total, 17 of 19 patients $(89 \%)$ responded to achalasia-type therapy.

\section{Discussion}

This study was designed to further assess the diagnostic yield of both STM and EGJ-DI findings in non-achalasia, non-obstructive dysphagia patients with signs of esophagogastric junction outflow obstruction. We were able to demonstrate that STM and EGJ-DI can identify EGJOO in symptomatic patients with normal SWS during HRM. Adding STM to HRM led to achalasia-type treatment in $76 \%$ of SWS-negative patients with a clinical response rate of $89 \%$.

This study is unique as it contains a group of patients with classical non-obstructive EGJOO according to CCv3 (SWS-group) and a group of symptomatic patients without signs of a major motility disorder during SWS (STM-group). In addition, all results were compared to asymptomatic patients (control group). This translates into the possibility of describing EGJ-DI values in EGJOO patients, which are diagnosed according to $\mathrm{CCv} 3$ [4], still regarded as state of the art in diagnostics of motility disorders, giving us the possibility to compare these values to those of symptomatic patients without the classical diagnosis of EGJOO (STM-group). By this, we were able to show that EGI-DI values $<3 \mathrm{~mm}^{2} / \mathrm{mmHg}$ in case of uneventful standard HRM (SWS-negative) identifies EGJOO in symptomatic patients.

STM has been shown to increase the diagnostic sensitivity of HRM for the identification of major motility disorders in patients with dysphagia $[7,8]$, but has not been implemented into the diagnostic guidelines of dysphagia management. Ang et al. highlighted that the disorder most often not observed during SWS was EGJOO, even though $90 \%$ of these patients reported esophageal pressurizations during the investigation [7]. Wang et al. further supported the diagnostic yield of STM by demonstrating an increased rate of EGJOO identification in symptomatic patients after fundoplication [23].

STM has been implemented in the routine assessment of dysphagia in our clinic. Accordingly, STM-group resembles a group of patients, which, without the additional investigation of STM, would have been left without a diagnosis and thus unexplained symptoms and by this without a clear therapeutic recommendation. Due to the underlying study design, the rate of additional diagnoses of EGJOO by STM cannot be answered. However, $60 \%$ of patients of the analyzed cohort (25/42) were only diagnosed by elevated IRP during STM (=SWS-negative), leading to achalasiatype treatment in 19 patients ( $76 \%$ ) as a consequence to the evaluation of STM. Due to a lack of specific documentation in our data base, a differentiation if a particular abnormal finding, rather than a combination of multiple results $(\mathrm{STM} \pm \mathrm{FLIP} \pm \mathrm{TBE})$ led to the treatment decision was not possible. However, only due to the STM-findings in this patient group, further investigations were initiated, enabling interventional treatment in a very carefully selected patient cohort.

To the best of our knowledge, the underlying study is one of two studies [14] focusing on the evaluation of EGJ-DI in EGJOO patients with FLIP technology, which has previously been shown to be of value in the workup of achalasia 
and eosinophilic esophagitis [24-26]. Recently Triggs et al. demonstrated FLIP to be helpful in the assessment of EGJOO in terms of identification of patients most likely to benefit from achalasia-type treatment [14]. The EGJ-DI values of our patients identified with EGJOO during STM showed a median EGJ-DI of $2.1 \mathrm{~mm}^{2} / \mathrm{mmHg}$. FLIP investigation helped us to identify patients who benefited from achalasia-type treatment, as demonstrated by a significant reduction of symptoms (expressed as a reduction in ES) and esophageal stasis post-interventionally. These results are in line with findings of Triggs et al., who recently demonstrated that patients diagnosed with EGJOO according to CCv3 with EGJ-DI $<2 \mathrm{~mm}^{2} / \mathrm{mmHg}$ were three-fold more likely to have radiologic evidence $(\geq 1 \mathrm{~cm}$ barium retention at $1 \mathrm{~min}$ ) for an EGJ disorder on TBE [14]. In addition, the same group of patients showed positive results (in terms of a reduced ES) after achalasia-type therapy. In contrast, all patients with EGJ-DI $>3 \mathrm{~mm}^{2} / \mathrm{mmHg}$ (median, 7.3; range 4.9-7.9) improved with conservative treatment. The authors argue that those patients' EGJ-DI were already within target range of achalasia-type treatment, making symptom relief as a consequence to a further reduction of EGJ outflow obstruction unlikely.

Not surprisingly, we found a significant difference in EGJ-DI between symptomatic and asymptomatic patients (Fig. 1). Further, we were able to demonstrate decreased EGJ-DI values in SWS-negative, but symptomatic patients (76\% had an EGJ-DI $<3 \mathrm{~mm}^{2} / \mathrm{mmHg}$ ). Median EGJ-DI values in the STM-group did not differ to those of EGJOO patients according to $\mathrm{CCv} 3$ (Fig. 2), demonstrating that the diagnosis of EGJOO during STM and SWS are comparable. The fact that STM-IRP showed a statistically significant association to EGJ-DI provides even further evidence that STM is able to identify EGJOO in case of uneventful SWS. In summary, our results further emphasize the diagnostic yield of FLIP and STM in assessing patients with dysphagia, since both investigations can identify EGJOO.

Today, no normative EGJ-DI values for the diagnosis of EGJOO exist. However, the clinical importance of EGJ-DI cannot be underestimated as its association with symptoms and esophageal retention (per TBE) may be stronger than conventional HRM findings [25]. In addition, in early stages of achalasia (and therefore EGJOO), endoscopy and TBE can be normal [27]. In accordance to the median EGJ-DI of $6.9 \mathrm{~mm}^{2} / \mathrm{mmHg}$ in asymptomatic patients found in this study, Carlson et al. reported a median EGJ-DI of $5.8 \mathrm{~mm}^{2} /$ $\mathrm{mmHg}$ in a prospective study of 20 asymptomatic volunteers [21]. Their conclusion of an EGJ-DI greater than $2.8 \mathrm{~mm}^{2} /$ $\mathrm{mmHg}$ to be normal, corresponding to results of earlier studies [13], goes along with our findings with a median EGJ-DI of $2.0 \mathrm{~mm}^{2} / \mathrm{mmHg}$ in all symptomatic patients.

In summary, in addition to the already established use in achalasia, FLIP technology seems to be of great diagnostic value in the management of SWS-negative dysphagia, with the potential of identifying a clinically relevant proportion of patients eligible for achalasia-type treatment.

This study is limited by its retrospective nature and the sample size, limiting its statistical power. In addition, the contractility pattern (absent, repetitive or retrograde) was not documented during all FLIP investigations and therefore no conclusions on the impact of EGJOO on esophageal contractility and resolution thereof can currently be made.

Our results emphasize the diagnostic yield of a standard test meal and FLIP in assessing patients with dysphagia. We not only described EGJ-DI values of classical EGJOO according to $\mathrm{CCv} 3$, but also of symptomatic patients with uneventful SWS evaluations during standard HRM. By this, we were able to demonstrate that FLIP may identify EGJOO in SWS negative patients, potentially during the index endoscopy. Last is not only of importance in terms of early diagnosis but also because many patients do not tolerate the HRM catheter. Moreover, the underlying study shows that STM increases the diagnostic sensitivity of HRM and helps diagnose EGJOO, resembling a cheap and valuable option whenever FLIP is unavailable or may help to carefully select symptomatic patients who should be referred to achalasia-type treatment.

With prospective, controlled studies pending, we believe that STM and FLIP are valuable tools in the assessment of non-achalasia and non-obstructive dysphagia patients.

Author Contributions FRM and LMF contributed equally to this study and should be considered joint first author. Both designed the study, gathered and analyzed data and wrote the manuscript. VS performed analytic calculations and critically reviewed the manuscript. LS, JMH, AT assisted data collection and critically reviewed the article. DP contributed to study design, data collection and interpretation as well as writing of the manuscript. DP additionally serves as the guarantor of the article.

Funding Open Access funding provided by Lib4RI - Library for the Research Institutes within the ETH Domain: Eawag, Empa, PSI \& WSL.

\section{Compliance with Ethical Standards}

Conflict of interest Daniel Pohl is a Consultant for Medtronic. All other authors have no conflict of interest. The authors received no specific funding for this work.

Ethical Approval This study was conducted ethically in accordance with the World Medical Association Declaration of Helsinki. All patients involved gave their written consent for the collection and analysis of patient-specific data. Datasets were analyzed after approval of the Zurich Ethics Committee (KEK-Nr: 2017-00930).

Open Access This article is licensed under a Creative Commons Attribution 4.0 International License, which permits use, sharing, adaptation, distribution and reproduction in any medium or format, as long as you give appropriate credit to the original author(s) and the source, 
provide a link to the Creative Commons licence, and indicate if changes were made. The images or other third party material in this article are included in the article's Creative Commons licence, unless indicated otherwise in a credit line to the material. If material is not included in the article's Creative Commons licence and your intended use is not permitted by statutory regulation or exceeds the permitted use, you will need to obtain permission directly from the copyright holder. To view a copy of this licence, visit http://creativecommons.org/licenses/by/4.0/.

\section{References}

1. Pandolfino JE, Gawron AJ. Achalasia: a systematic review. JAMA. 2015;313(18):1841-52.

2. Clayton SB, Patel R, Richter JE. Functional and anatomic esophagogastic junction outflow obstruction: manometry, timed barium esophagram findings, and treatment outcomes. Clin Gastroenterol Hepatol. 2016;14(6):907-11.

3. Schindler V, Runggaldier D, Bianca A, Becker AS, Murray F, Savarino E, et al. Opioid treatment and excessive alcohol consumption are associated with esophagogastric junction disorders. J Neurogastroenterol Motil. 2019;25(2):205-11.

4. Kahrilas PJ, Bredenoord AJ, Fox M, Gyawali CP, Roman S, Smout AJ, et al. The chicago classification of esophageal motility disorders, v3.0. Neurogastroenterol Motil. 2015;27(2):160-74.

5. Xiao Y, Kahrilas PJ, Nicodeme F, Lin Z, Roman S, Pandolfino JE. Lack of correlation between HRM metrics and symptoms during the manometric protocol. Am J Gastroenterol. 2014;109(4):521-6.

6. Sweis R, Anggiansah A, Wong T, Brady G, Fox M. Assessment of esophageal dysfunction and symptoms during and after a standardized test meal: development and clinical validation of a new methodology utilizing high-resolution manometry. Neurogastroenterol Motil. 2014;26(2):215-28.

7. Ang D, Misselwitz B, Hollenstein M, Knowles K, Wright J, Tucker E, et al. Diagnostic yield of high-resolution manometry with a solid test meal for clinically relevant, symptomatic oesophageal motility disorders: serial diagnostic study. Lancet Gastroenterol Hepatol. 2017;2(9):654-61.

8. Hollenstein M, Thwaites P, Butikofer S, Heinrich H, Sauter M, Ulmer I, et al. Pharyngeal swallowing and oesophageal motility during a solid meal test: a prospective study in healthy volunteers and patients with major motility disorders. Lancet Gastroenterol Hepatol. 2017;2(9):644-53.

9. Carlson DA, Kahrilas PJ, Lin Z, Hirano I, Gonsalves N, Listernick Z, et al. Evaluation of esophageal motility utilizing the functional lumen imaging probe. Am J Gastroenterol. 2016;111(12):1726-35.

10. Kwiatek MA, Pandolfino JE, Hirano I, Kahrilas PJ. Esophagogastric junction distensibility assessed with an endoscopic functional luminal imaging probe (EndoFLIP). Gastrointest Endosc. 2010;72(2):272-8.

11. McMahon BP, Frokjaer JB, Liao D, Kunwald P, Drewes AM, Gregersen $\mathrm{H}$. A new technique for evaluating sphincter function in visceral organs: application of the functional lumen imaging probe (FLIP) for the evaluation of the oesophago-gastric junction. Physiol Meas. 2005;26(5):823-36.

12. Rohof WO, Hirsch DP, Kessing BF, Boeckxstaens GE. Efficacy of treatment for patients with achalasia depends on the distensibility of the esophagogastric junction. Gastroenterology. 2012;143(2):328-35.

13. Pandolfino JE, de Ruigh A, Nicodeme F, Xiao Y, Boris L, Kahrilas PJ. Distensibility of the esophagogastric junction assessed with the functional lumen imaging probe (FLIP) in achalasia patients. Neurogastroenterol Motil. 2013;25(6):496-501.

14. Triggs JR, Carlson DA, Beveridge C, Kou W, Kahrilas PJ, Pandolfino JE. Functional luminal imaging probe panometry identifies achalasia-type esophagogastric junction outflow obstruction. Clin Gastroenterol Hepatol. 2019;18(10):2209-17.

15. Ponds FA, Bredenoord AJ, Kessing BF, Smout AJ. Esophagogastric junction distensibility identifies achalasia subgroup with manometrically normal esophagogastric junction relaxation. Neurogastroenterol Motil. 2017;29(1):e12908.

16. Pandolfino JE, El-Serag HB, Zhang Q, Shah N, Ghosh SK, Kahrilas PJ. Obesity: a challenge to esophagogastric junction integrity. Gastroenterology. 2006;130(3):639-49.

17. Pandolfino JE, Ghosh SK, Rice J, Clarke JO, Kwiatek MA, Kahrilas PJ. Classifying esophageal motility by pressure topography characteristics: a study of 400 patients and 75 controls. Am J Gastroenterol. 2008;103(1):27-37.

18. Sweis R, Anggiansah A, Wong T, Kaufman E, Obrecht S, Fox $M$. Normative values and inter-observer agreement for liquid and solid bolus swallows in upright and supine positions as assessed by esophageal high-resolution manometry. Neurogastroenterol Motil. 2011;23(6):509-e198.

19. Carlson DA, Hirano I. Application of the functional lumen imaging probe to esophageal disorders. Curr Treat Options Gastroenterol. 2017; 15(1):10-25.

20. Bianca A, Schindler V, Schnurre L, Murray F, Runggaldier D, Gyawali CP, et al. Endoscope presence during endoluminal functional lumen imaging probe (FLIP) influences FLIP metrics in the evaluation of esophageal dysmotility. Neurogastroenterol Motil. 2020;32(6): 13823.

21. Carlson DA, Kou WJ, Lin ZY, Hinchcliff M, Thakrar A, Falmagne $\mathrm{S}$, et al. Normal values of esophageal distensibility and distensioninduced contractility measured by functional luminal imaging probe panometry. Clin Gastroenterol Hepatol. 2019;17(4):674681.e1.

22. Schnurre L, Murray F, Schindler V, Runggaldier D, Fischbach L, Bordier V, et al. Short-term outcome after singular hydraulic EsoFLIP dilation in patients with achalasia: a feasibility study. Neurogastroenterol Motil. 2020. https://doi.org/10.1111/ nmo. 13864.

23. Wang YT, Tai LF, Yazaki E, Jafari J, Sweis R, Tucker E, et al. Investigation of dysphagia after antireflux surgery by high-resolution manometry: impact of multiple water swallows and a solid test meal on diagnosis, management, and clinical outcome. Clin Gastroenterol Hepatol. 2015;13(9):1575-83.

24. Carlson DA, Hirano I, Zalewski A, Gonsalves N, Lin Z, Pandolfino JE. Improvement in esophageal distensibility in response to medical and diet therapy in eosinophilic esophagitis. Clin Transl Gastroenterol. 2017;8(10):e119.

25. Hirano I, Pandolfino JE, Boeckxstaens GE. Functional lumen imaging probe for the management of esophageal disorders: expert review from the clinical practice updates committee of the AGA institute. Clin Gastroenterol Hepatol. 2017;15(3):325-34.

26. Carlson DA, Gyawali CP, Kahrilas PJ, Triggs JR, Falmagne S, Prescott J, et al. Esophageal motility classification can be established at the time of endoscopy: a study evaluating real-time functional luminal imaging probe panometry. Gastrointest Endosc. 2019;90(6):915-23.e1.

27. Howard PJ, Maher L, Pryde A, Cameron EW, Heading RC. Five year prospective study of the incidence, clinical features, and diagnosis of achalasia in Edinburgh. Gut. 1992;33(8):1011-5.

Publisher's Note Springer Nature remains neutral with regard to jurisdictional claims in published maps and institutional affiliations. 
Fritz Ruprecht Murray MD

Lara Maria Fischbach MD

Valeria Schindler MD

Larissa Schnurre MD
Juliane Marie Hente MD

Aurora Tatu MD

Daniel Pohl MD 